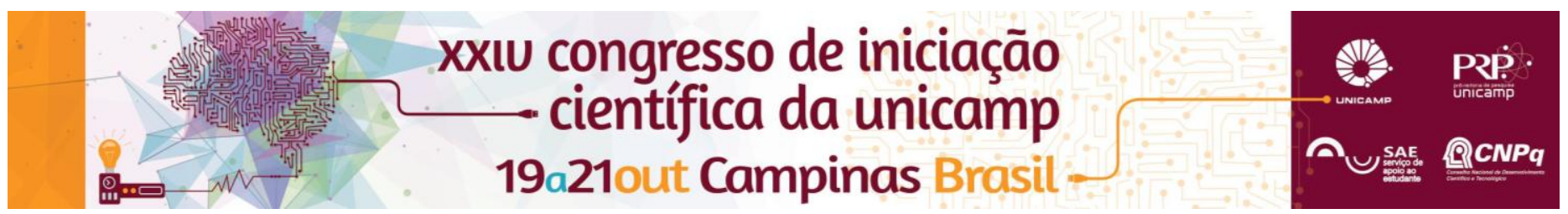

\title{
Organização e análise de biomarcadores ao longo do Campeonato Brasileiro (Série B) 2015
}

\author{
Isabel Z. Fonseca*, Denise Vaz de Macedo, René Brenzikofer
}

\section{Resumo}

Em modalidades coletivas o resultado do time depende do desempenho individual de cada atleta, que está associado as adaptações moleculares que o treinamento pode gerar. Essas adaptações foram monitoradas através de resultados de testes físicos e/ou biomarcadores sanguíneos, e comparadas com intervalos de referência e diferenças crítica, possibilitando discriminar aqueles cuja sobrecarga esteja sendo excessiva. O tamanho dos banco de dados oriundo dos testes dificulta a análise. Para contornar essa dificuldade usamos o "Aplicativo Labex Esporte", que permitiu a visualização dos dados individuais ou coletivos de diversos analitos, transversalmente ou longitudinalmente, comparando-os com os respectivos intervalos de referencia e diferença crítica.

\section{Palavras-chave:}

Futebol, Banco de Dados, Análise Estatística

\section{Introdução}

Em esportes coletivos, como o futebol, um espírito de grupo anima o time, já que os atletas treinam e competem juntos. Porém, uma lesão ou outros problemas de saúde de um atleta podem afetar a eficiência da equipe inteira. Justifica-se o acompanhamento longitudinal da carga de esforço, das adaptações fisiológicas e bioquímicas e do desempenho físico dos atletas individualmente. No entanto, o tamanho dos bancos de dados gerados dificulta a visualização e extração das informações. Pesquisadores do "Labex" desenvolveram o "Aplicativo Labex Esporte" para a visualização e análise de dados provenientes do monitoramento sanguíneo transversal e longitudinal de grandes grupos de atletas.

O objetivo deste projeto foi gerenciar o "Aplicativo Labex Esporte" no monitoramento da evolução das análises hematológicas e bioquímicas individuais dos jogadores do time de futebol, Mogi Mirim Esporte Clube ao longo do Campeonato Brasileiro série $\mathrm{B}$, e realizar a posterior análise dos dados.

\section{Resultados e Discussão}

Ao longo do campeonato, os jogadores do time foram submetidos a 4 coletas tanto sanguíneas quanto de composição corporal (CC). A Tabela 1 apresenta os momentos das avaliações e a quantidade de jogadores que participaram de cada coleta.

Tabela 1: Dados referentes às coletas de sangue como data, variação de jogadores a cada coleta e número de analitos analisados.

\begin{tabular}{ccccc} 
Coleta & Data & \multicolumn{2}{c}{$\begin{array}{c}\text { No atletas } \\
\text { Total/ Novos }\end{array}$} & № de Analitos \\
\hline 1 & 05/mai & 31 & 0 & 25 \\
2 & $09 /$ jun & 35 & 7 & 25 \\
3 & $18 /$ ago & 35 & 13 & 25 \\
4 & 22/set & 32 & 7 & 25
\end{tabular}

Com a tabela, percebe-se uma alta rotatividade de jogadores. Ao longo do campeonato, o clube também apresentou mudanças na comissão técnica, mudança de diretoria, e até mesmo a venda do clube.

No monitoramento hematológico os jogadores não apresentaram valores fora dos intervalos de referências. Nas análises bioquímicas, por exemplo, a Figura 1 apresenta as atividades das enzimas CK e AST no soro.

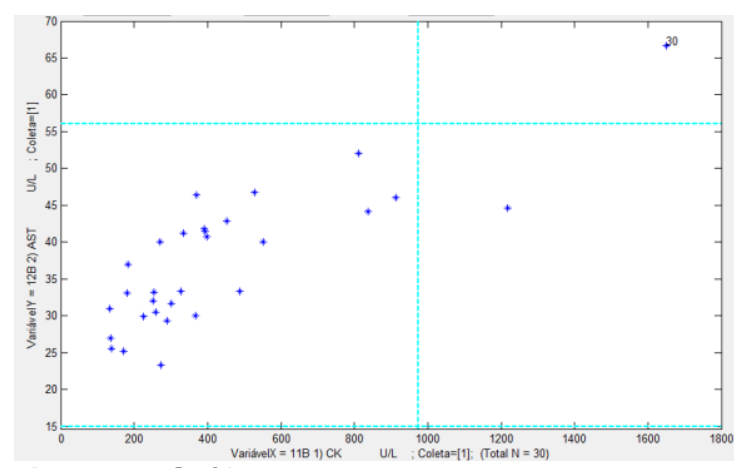

Figura 1: Gráfico gerado pelo aplicativo, onde a abscissa representa o analito Creatina Quinase (CK) e a ordenada o analito AST, ambos obtidos na primeira coleta

Notamos que um atleta (№ 30) apresentou valores fora do intervalo de referência (linhas tracejadas) para ambas enzimas. Isto indica um forte potencial lesivo neste jogador, fato imediatamente reportado a comissão técnica. Em relação ao perfil lipídico, a pesquisa também mostrou que muitos jogadores apresentaram valores altos de LDLcolesterol, e valores baixos de HDL-colesterol, que podem estar relacionados à falta de nutricionista na equipe.

\section{Conclusões}

O Aplicativo Labex Esporte foi eficiente nas análises individuais e longitudinais dos parâmetros hematológicos, bioquímicos e CC de um time de futebol ao longo do Campeonato Brasileiro. Com o aplicativo, informações relevantes sobre os jogadores foram extraídas e permitiram reajustes no treinamento e jogos.

\section{Agradecimentos}

Ao PIBIC / CNPQ pela bolsa de iniciação científica. 